\title{
TRANSIENT THERMAL ANALYSIS FOR RADIOACTIVE LIQUID MIXING OPERATIONS IN A LARGE-SCALED TANK
}

\author{
Si Y. Lee* and Frank G. Smith, III \\ Savannah River National Laboratory \\ Savannah River Nuclear Solutions, LLC \\ Aiken, SC 29808 \\ * si.lee@srnl.doe.gov; frank02.smith@srnl.doe.gov
}

\begin{abstract}
A transient heat balance model was developed to assess the impact of a Submersible Mixer Pump (SMP) on radioactive liquid temperature during the process of waste mixing and removal for the high-level radioactive materials stored in Savannah River Site (SRS) tanks. The model results will be mainly used to determine the SMP design impacts on the waste tank temperature during operations and to develop a specification for a new SMP design to replace existing longshaft mixer pumps used during waste removal. The present model was benchmarked against the test data obtained by the tank measurement to examine the quantitative thermal response of the tank and to establish the reference conditions of the operating variables under no SMP operation. The results showed that the model predictions agreed with the test data of the waste temperatures within about $10 \%$.
\end{abstract}

KEY WORDS: Transient Heat Balance, Modeling Analysis, Sludge Mixing, Submersible Pump

\section{INTRODUCTION}

Waste storage tanks in $\mathrm{F}$ and $\mathrm{H}$ areas at Savannah River Site (SRS) are 0.75 million-gallon, single-wall, Type-I tanks. The tank is a $75 \mathrm{ft}$ diameter, flat-bottomed, cylindrical tank with a height of about $24.5 \mathrm{ft}$. The tank consists of a primary steel tank and secondary containment. The primary tank shell is made of 0.5-in thick carbon steel, and is constructed in accordance with Section VIII of the ASME Boiler Code for Unfired Pressure Vessels. The secondary containment is a 0.5 -in thick, 80 -ft diameter and 5-ft high steel pan. Inside the primary tank, there are cooling coils, a valve housing to control the coolant flow of the cooling coils, and 12 structural support columns internal to the tank as shown in Fig. 1. A total of 36 cooling coils are supported from the roof including two horizontal coils across the tank bottom, but only about 12 coils in Tank 11 are actually functional during normal operations. Each cooling coil is 2-in Sch. 40 carbon steel, and is made of seamless pipe. It is proposed to use a Submersible Mixer Pump (SMP) to suspend and mobilize the waste in typical type-I waste tanks for sludge removal operations.

The waste tank requires more than one slurry pump during sludge removal operations. Each pump has a bottom suction with two opposing discharge nozzles. The pump is normally submerged to approximately the level of the sludge, allowing a recirculating mixture of sludge and water to serve as the feed flow. The pump nozzle is placed about 30 inches above the tank bottom. Previous results $[1,2]$ show that the pump location is not sensitive to the mixing performance of waste sludge within the 30-in elevation. Therefore, pump location can be assumed to have negligible impact on thermal balance due to non-uniform pump dissipation inside tank. 
The waste in the tank consists of salt and sludge. The salt was removed by dissolution in water and transferred to other tanks for storage. The remaining sludge layer settled near the bottom and will be hydraulically mobilized by SMP and transferred to other tanks by a Submersible Transfer Pump (STP). Waste sludge contained in the tank has high decay heat loads due to the presence of radioactive nuclides. The present work considers the heat loads of tank waste caused by the dissipation of submersible pumps and radioactive decay of waste sludge. Average and maximum decay heat loads of the type-I waste tanks in the $\mathrm{F}$ and $\mathrm{H}$ areas are about 22 and 43 $\mathrm{W} / \mathrm{m}^{3}$, respectively.

High-level Waste Engineering is currently in the process of developing a specification for a new SMP design to replace existing long-shaft mixer pumps used during waste removal. Prior to releasing the specification out for bids, it was considered necessary to perform a preliminary heat balance study to determine how the SMP design impacts waste tank temperature during waste removal operations. The primary objective of the present work is to perform a heat balance study for type-I waste tank to assess the impact of using SMP's during waste removal. The temperature results calculated by the model will be used to evaluate the temperatures of the slurry waste under various tank operating conditions.

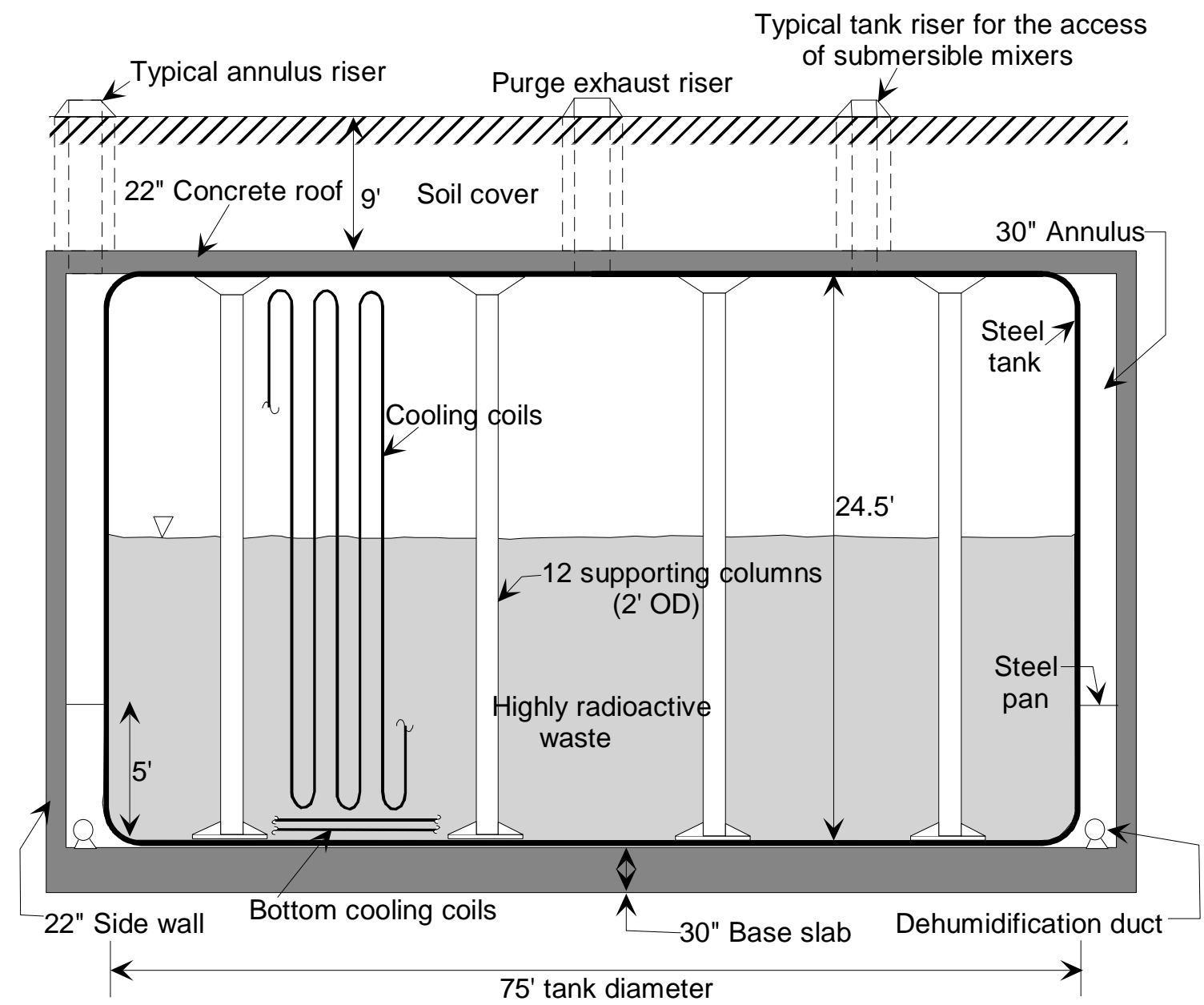

Figure 1. Typical type-I waste tank (750,000 gallons tank) used for the present analysis 


\section{MODELING APPROACH AND GOVERNING EQUATIONS}

A lumped parametric approach was taken to develop a transient model for the heat balance study for type-I waste tanks such as Tank 11, during waste removal by Submersible Mixer Pumps (SMP). The tank domain used in the present model consists of two SMP's for sludge mixing, one STP for the waste removal, cooling coil system with 36 coils, and purge gas system. The sludge waste contained in Tank 11 also has a decay heat load of about $43 \mathrm{~W} / \mathrm{m}^{3}$ mainly due to the emission of radioactive gamma rays. All governing equations were established by an overall energy balance for the tank domain, and they were numerically solved. Detailed descriptions for the modeling assumptions and governing equations are provided below.

\subsection{Model Assumptions and Overall Energy Balance}

A transient heat balance model used single waste temperature model, which represents one temperature for the entire waste liquid domain contained in the tank at each transient time. Detailed descriptions for the modeling assumptions are provided below.

- Waste fluid inside 75-ft tank is always well-mixed thermally so that bulk fluid temperature and properties can be represented as volume-averaged values since submersible mixing and transfer pumps are in operation.

- Heat transfer effect from the cooling coil surface above the free surface, which is exposed to purge gas, is assumed to be negligible for conservatism.

- Structural materials such as supporting columns and pump risers are always in thermal equilibrium with slurry fluid since scoping calculations show that thermal diffusivities of structural materials are at least about $10^{4}$ larger than that of waste fluid.

- Gas above the free surface of tank liquid consists of a well mixed air-vapor mixture combined with relative humidity.

- Air and vapor of purge gas mixture obey perfect-gas behavior, and they follow the GibbsDalton law for the gas mixture.

- Waste fluid follows the behavior of water evaporative cooling at the free surface.

- Soil region surrounding the tank is assumed to be infinite heat sink.

Based on the main assumptions mentioned above, an overall energy balance for the control volume of type-I SRS waste tank becomes:

$$
\begin{aligned}
\rho_{l} C_{p l} V \frac{d T_{\text {liq }}}{d t}= & \rho_{l} C_{p l} \dot{V}_{l, i n}\left(T_{l i q, \text { in }}-T_{\text {liq }}\right) \\
& +Q_{S M P}+Q_{S T P}+Q_{\text {decay }}-Q_{\text {surf }}-Q_{\text {coil }}-Q_{\text {wall }}-Q_{\text {bottom }}-Q_{\text {str }}
\end{aligned}
$$

In Eq. (1) heat source terms are two SMP's $Q_{\text {SMP }}$, one STP $Q_{\text {STP }}$, and radioactive decay heat source $\mathrm{Q}_{\text {decay. }}$. In the balance equation, heat sink terms are heat loss rate from the top liquid surface of waste tank $\mathrm{Q}_{\text {surf }}$, heat transfer rate across the cooling coil surface due to convective coolant flow $\mathrm{Q}_{\text {coil }}$, and heat loss rates from the external surfaces of the tank side and bottom walls $\mathrm{Q}_{\text {wall }}$ and $\mathrm{Q}_{\text {bottom. }}$. $\mathrm{Q}_{\text {str }}$ represents transient heat absorbed into the structural material, and it is assumed to be negligibly small since preliminary study shows that thermal diffusivity for tank 
structural material such as concrete or steel is at least $10^{4}$ times larger than that of water. Thus, transient temperature of bulk waste fluid, $T_{\text {liq }}$, is determined by the energy balance of heat sources and sinks through the tank domain boundary when sludge flow $v_{l, \text { in }}$ of temperature $T_{\text {liq,in }}$ comes into the tank as shown in Eq. (1). Detailed discussions for the heat source and sink terms are provided below.

\subsection{Heat Source and Sink Terms}

As discussed earlier, heat sources ( $\mathrm{Q}_{\mathrm{smp}}, \mathrm{Q}_{\mathrm{stP}}$, and $\left.\mathrm{Q}_{\text {decay }}\right)$ used in Eq. (1) are due to the presence of two SMP's, one STP, and decay heat source of radioactive waste contents contained in type-I tank. Typical decay load considered in the present work is about $22 \mathrm{~W} / \mathrm{m}^{3}$. For the present analysis, Tank 11 decay load will be used as the referenced decay heat load since the tank has the highest decay heat source in terms of overall tank heat load. Average decay heat of the tanks located in F area will be also used in the sensitivity analysis. Each SMP used in the analysis considers high pumping power in the range of $225 \mathrm{HP}$ to $350 \mathrm{HP}$. Detailed operating conditions for the mixing pumps will be provided later. Detailed discussions for the heat sink terms used in the overall balance equation, Eq. (1), are provided below.

\subsection{Heat loss rate at the top surface of tank waste $\left(Q_{\text {surf }}\right)$}

Based on the ideal gas assumption of the purge gas mixture, the mole fraction of vapor in the mixture $\left(X_{H 2 O}\right)$ is

$$
X_{\mathrm{H} 2 \mathrm{O}}=\frac{m_{\mathrm{H} 2 \mathrm{O}} M_{\text {mixture }}}{M_{\mathrm{H} 2 \mathrm{O}}}
$$

In Eq. (2) the equivalent molecular weight of the mixture is calculated as

$$
M_{\text {mixture }}=X_{\mathrm{H}_{2} \mathrm{O}} M_{\mathrm{H} 2 \mathrm{O}}+X_{\text {air }} M_{\text {air }}
$$

For a perfect gas mixture, mole fraction is related to the volume and partial pressure of each component. That is,

$$
X_{H 2 O}=\frac{V_{H 2 O}}{V}=\frac{P_{H 2 O}}{P}
$$

In Eq. (4) $V_{\mathrm{H}_{2} \mathrm{O}}$ is the volume which substance vapor $\left(\mathrm{H}_{2} \mathrm{O}\right)$ alone would occupy at the temperature and pressure of the mixture. After algebraic manipulation of Eq. (4) and use of molecular weight ratio of air to vapor gases, the relation to give the mass concentration of vapor in the mixture is

$$
m_{\mathrm{H} 2 \mathrm{O}}=\left(\frac{P_{\mathrm{H} 2 \mathrm{O}}}{1.611 P-0.611 P_{\mathrm{H} 2 \mathrm{O}}}\right)
$$

In Eq. (5), molecular weights for $\mathrm{M}_{\mathrm{H} 2 \mathrm{O}}$ and $\mathrm{M}_{\text {air }}$ are used as 18 and 29 . In the present calculations, relative humidity $\phi$ is provided as

$$
\phi=\left(\frac{P_{H 2 O}}{P_{H 2 O, s a t}}\right)
$$

In Eq. (6) $P_{\mathrm{H} 2 \mathrm{O} \text {,sat }}$ is the saturated vapor pressure of water corresponding to the transient temperature. An empirical correlation for the saturation pressure [3] in terms of absolute water temperature $\mathrm{T}$ is: 
$P_{\text {H2O,sat }}=\exp \left(-38.874+0.29129 T-5.7014 \times 10^{-4} T^{2}+4.0606 \times 10^{-7} T^{3}\right)$

In Eq. (7), saturation pressure $P_{\mathrm{H} 2 \mathrm{O} \text {,sat }}$ should be in $\mathrm{N} / \mathrm{m}^{2}$ (or $\mathrm{Pa}$ ), when the absolute temperature $\mathrm{T}$ is used in $\mathrm{K}$.

In the present work, it is assumed that liquid is mainly evaporated within a boundary layer near the top surface of the tank waste. In this case, liquid mass concentrations in the boundary layer are controlled by diffusion-driven mechanism. Mass flux $\left(\dot{m}^{\prime \prime}\right)$ due to evaporation across the top interfacial surface can be written in terms of water mass fraction $\left(m_{\mathrm{H} 2 \mathrm{O}}\right)$.

$\dot{m}^{\prime \prime}=g\left(\frac{m_{\mathrm{H} 2 \mathrm{O}, \infty}-m_{\mathrm{H} 2 \mathrm{O}}}{m_{\mathrm{H} 2 \mathrm{O}}-m_{\text {total }}}\right)=g B$

In Eq. (8) $\mathrm{g}$ is the mass transfer conductance $\left(\mathrm{kg} / \mathrm{m}^{2} \mathrm{sec}\right)$, corresponding to a heat transfer coefficient, and $m_{\text {total }}$ is total concentration of vapor, which is equivalent to unity since water is a single-phase fluid. A literature correlation for the mass transfer conductance g [4] was used to estimate the evaporative mass of fluid at the top surface of the type-I waste tank. That is,

$g=0.0287 \rho_{\infty} u_{\infty} \operatorname{Pr}^{-0.4} \operatorname{Re}^{-0.2} \frac{\ln (1+B)}{B}$

This equation is applicable only to the fluid temperature less than its boiling temperature.

From the energy balance at the interfacial boundary of the free surface as shown in Fig. 2, total heat loss at the top surface of waste liquid $Q_{\text {surf }}$ can be estimated in terms of sensible heat transfer $Q_{\text {sens }}$ and evaporative cooling $Q_{\text {evap }}$.

$Q_{\text {surf }}=Q_{\text {sens }}+Q_{\text {evap }}$

When constitutive equations for the sensible heat loss $Q_{\text {sens }}$ and the evaporative cooling $Q_{\text {evap }}$ are provided, total heat loss at the surface of waste $Q_{\text {surf }}$ can be quantified.

$Q_{\text {sens }}=h_{\text {surf }} A\left(T_{\text {liq }}-T_{\text {gas }}\right)$

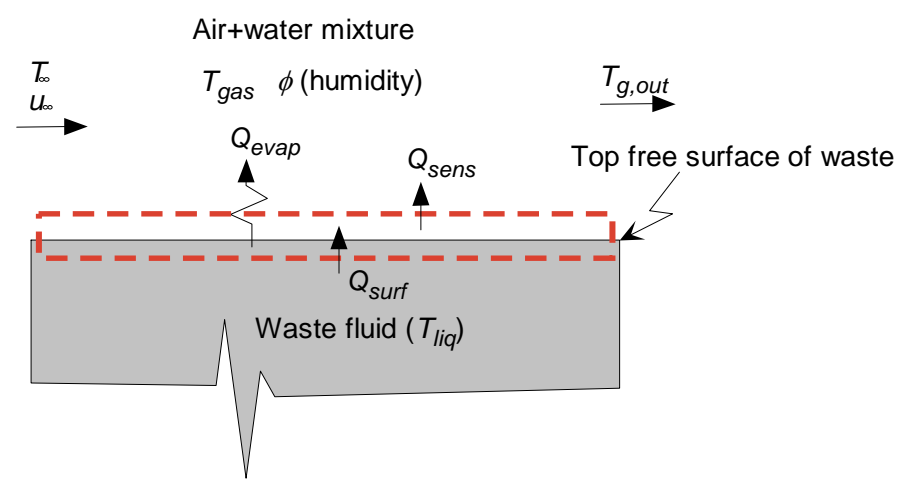

Figure 2. Control volume at the phase interface for the energy balance equation

In Eq. (11), the transient bulk gas temperature above the free surface, $T_{\text {gas }}$, can be computed by an energy transport equation associated with total heat transfer at the free surface $Q_{\text {surf. }}$ That is: 
$\rho_{g} V_{g} C_{p g} \frac{d T_{g a s}}{d t}=\rho_{\infty} \omega_{g, \infty} C_{p g}\left(T_{\infty}-T_{g a s}\right)+Q_{\text {surf }}$

In Eq. (12) $\omega_{g, \infty}$ is the purge air flowrate at the inlet of the purge gas system. The exit gas flowrate $\omega_{g, t}$ can be estimated by the mixed flow of purge gas and evaporation flowrates. In this case, the gas temperature at the exit of purge gas system, $T_{g, \text { out }}$, is assumed to be equal to the bulk gas temperature $T_{\text {gas }}$. Gas density is computed using the ideal gas law.

In Eq. (11), the heat transfer coefficient at the surface $\left(h_{\text {surf }}\right)$ was estimated by the literature correlation [7] for the cooled plate facing upward. That is,

$h_{\text {surf }}=0.61\left(\Delta T / L^{2}\right)^{0.2}$

For a typical condition of the present analysis, $\mathrm{h}_{\text {surf }}$ was found to be about $0.5 \mathrm{~W} / \mathrm{m}^{2} \mathrm{sec}$.

The evaporative cooling term $Q_{\text {evap }}$ is expressed in terms of mass flux $\dot{m}$ " and enthalpy for latent heat of evaporation $i_{f g}$.

$Q_{\text {evap }}=\dot{m}^{\prime \prime} A\left\{i_{\text {fg }}+C_{p l}\left(T_{\text {liq }}-T_{\text {gas }}\right)\right\}$

In Eq. (14) $C_{p l}$ and $T_{\text {liq }}$ are specific heat and temperature of liquid, respectively. In this case evaporative mass flux term can be evaluated by the constitutive equations, Eq. (5) through (9), for the estimation of total heat loss due to purge gas at the top free surface of waste tank. It should be emphasized that the empirical correlation, Eq. (9), for evaporative mass flux due to the purge gas flow is valid only for single-phase liquid. If fluid temperature exceeds its boiling temperature, the evaporative mass transfer at the free surface is assumed to be a constant value corresponding to the boiling temperature since the present work is concerned only with nonboiling situation for the evaluation of thermal impact due to operation of the SMP mixers.

\subsection{Heat loss rate at the surface of cooling coil $\left(Q_{\text {coil }}\right)$}

For the quantitative evaluation of heat transfer through the cooling coil system with chemical deposition on the outer surface of the coil as shown in Fig. 2, energy balance equations for the modeling boundary of cooling coil are constructed for the normal operating conditions with forced convective coolant flow. That is,

$$
\begin{aligned}
& \left(T_{f}-T_{w c 1}\right)=\frac{Q_{\text {coil }}}{h_{f o} A_{c w o}}=R_{f o} Q_{\text {coil }} \\
& \left(T_{w c 1}-T_{w c 2}\right)=\frac{c Q_{\text {coil }}}{k_{c} A_{c m}}=R_{c} Q_{\text {coil }} \\
& \left(T_{w c 2}-T_{c m}\right)=\frac{Q_{\text {coil }}}{h_{f i} A_{c w i}}=R_{f i} Q_{\text {coil }}
\end{aligned}
$$

In Eqs. (15) to (17), transient energy accumulation during the heat transfer across the coil surface is assumed to be negligible. The heat transfer resistances, $R_{f o}, R_{c}$, and $R_{f i}$, are for thermal boundary layer external to the coil surface, for the chemical deposition layer of thickness c, and 
for thermal boundary layer of the inner surface of the coil, respectively. $A_{c w o}$ and $A_{c w i}$ are total wetted areas of the outer and inner walls of the cooling coils, respectively. $A_{c m}$ in Eq. (17) is logarithmic average of area for an annular deposition layer of the outer coil diameter $d_{c o}$.

$$
A_{c m}=\frac{2 \pi c L_{w c}}{\ln \left(\frac{d_{c o}+2 c}{d_{c o}}\right)}=\frac{2 c A_{c w o}}{d_{c o} \ln \left(\frac{d_{c o}+2 c}{d_{c o}}\right)}
$$

Wetted surface area of the cooling coil $\left(A_{c w o}\right)$ in Eq. (18) is dependent on transient tank level $\left(L_{w c}\right)$. Important elevation levels for the type-I tank are shown in Fig. 3. In the present analysis, nominal tank level is used as 100 inches from the tank bottom as provided by the customer [1]. Other notations of the variables used in the equations are presented in Fig. 3. In Eq. (17), mean bulk temperature of coil coolant flow, $T_{c m}$, is used as an arithmetic average of the inlet and outlet temperatures, $T_{1}$ and $T_{2}$.

$$
T_{c m}=\frac{1}{2}\left(T_{1}+T_{2}\right)
$$

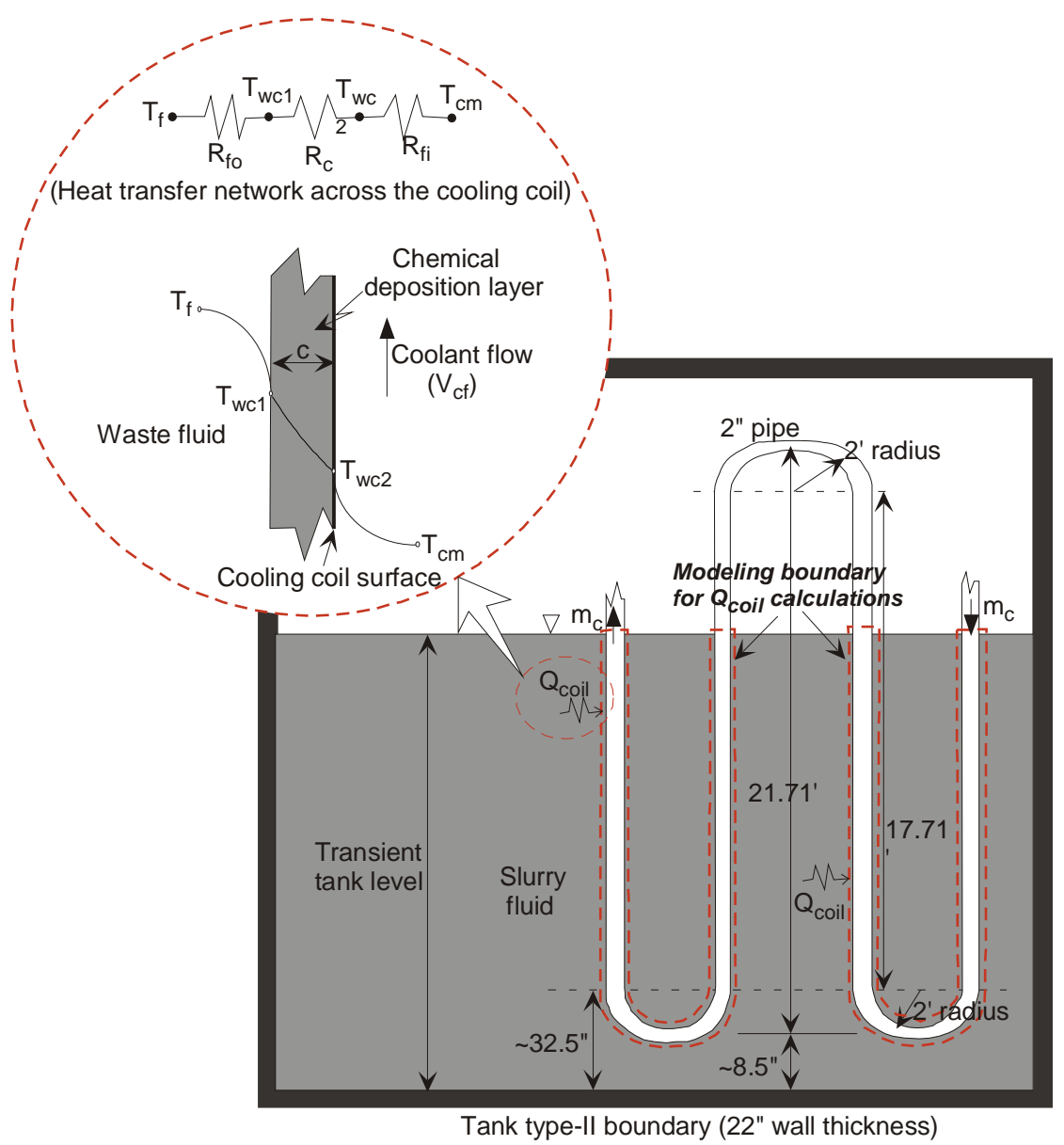

Figure 3. Modeling boundary for heat transfer calculations due to the presence of cooling coil flow $\left(Q_{\text {coil }}\right)$ 
In this case, when nominal coolant flow $v_{c f}$ is given, temperature difference between the inlet and exit of the cooling coil flow is related to the convective energy transfer through the cooling coil system with $N_{c}$ active cooling coils out of total 36 available cooling coils. The horizontal cooling coil located near the bottom of the tank, which is always wet regardless of the tank level, is assumed to be inactive as one of the reference operating conditions for conservative estimation. However, the sensitivity analysis for the active bottom cooling coil will be performed.

$\left(T_{2}-T_{1}\right)=\frac{Q_{\text {coil }}}{N_{c} \rho_{f} v_{c f} C_{p}}$

After algebraic manipulations of the equations, Eq. (15) to Eq. (19), the resulting equation for the heat transfer rate due to the presence of the $N_{c}$ cooling coils $\left(Q_{\text {coil }}\right)$ can be obtained in terms of waste fluid temperature $T_{f}$ and cooling coil inlet temperature $T_{1}$.

$Q_{\text {coil }}=\left(T_{f}-T_{1}\right)\left(\frac{1}{h_{f o} A_{c w o}}+\frac{c}{k_{c} A_{c m}}+\frac{1}{h_{f i} A_{c w i}}+\frac{0.5}{N_{c} \rho_{f} \dot{v}_{c f} C_{p}}\right)^{-1}$

In Eq. (21) heat transfer coefficient for the external surface of cooling coil $\left(h_{f o}\right)$ was estimated by the theoretical formulation for constant heat flux with laminar flow condition found in the literature [4]. That is,

$h_{f o}=4.364 \frac{k_{f}}{d_{c o}}$

In Eq. (22) $k_{f}$ is thermal conductivity for waste fluid. In this case material and thermal properties of water were used for the estimation of the heat loss across the external surfaces of the cooling coils.

Heat transfer coefficient for the inner wall surface of the cooling coil $\left(h_{f i}\right)$ in Eq. (21) was evaluated by the literature correlation for the forced convection [8], which is known as DittusBoelter equation. That is,

$h_{f i}=0.023\left(\frac{k_{f w}}{d_{c i}}\right) \operatorname{Re}_{d}^{0.8} \operatorname{Pr}^{0.4}$

In Eq. (23) $k_{f w}$ is thermal conductivity for water. Non-dimensional numbers of Reynolds number $\left(\mathrm{Re}_{\mathrm{d}}\right)$ and Prandtl number $(\mathrm{Pr})$ in the equation were defined in terms of water properties and cooling coil diameter. For the referenced nominal conditions, Reynolds number was found to be about $10^{5}$, which corresponds to the turbulent flow regime. Thus, the empirical correlation Eq. (23) is applicable to the present work.

\subsection{Heat loss rates through the side wall and bottom of $\operatorname{tank}\left(Q_{\text {wall }}\right.$ and $\left.Q_{\text {bottom }}\right)$}

For the evaluation of heat transfer across the side wall of type-I waste tank, a plane wall is assumed to be exposed to a hot waste fluid $1, T_{\mathrm{f} 1}$, on one side and a cooler fluid $2, T_{\mathrm{f} 2}$, on the other side for the evaluation of overall heat transfer coefficient U. In this case the heat transfer processes for the wall and bottom regions are represented by the resistance network.

$Q_{1 \rightarrow 2}=Q_{\text {wall }}=U\left(T_{f 1}-T_{f 2}\right)$ 
In Eq. (24) overall heat transfer coefficient U can be computed for thermal properties of the wall materials.

Now, all constitutive equations associated with the transient heat balance equation, Eq. (1), are complete. In this case, transient tank boundary conditions are required to compute transient temperature for each material region of the waste tank system. Transient responses of heat loads are dependent on initial volume of the waste stored in the tank. Waste volumes for the ranges of tank levels to be used in the analysis are calculated for various liquid levels.

\section{RESULTS AND DISCUSSIONS}

Based on the analysis methodology and the modeling assumptions, a transient heat balance model has been developed by using a lumped parametric approach. Overall energy balance equations for typical SRS type-I waste tank such as Tank 11 were constructed for the modeling domain. The modeling governing equations were solved using Aspen Custom Modeler $\left(\mathrm{ACM}^{\mathrm{TM}}\right)$ software for the transient boundary conditions provided by the operational procedure for the sludge mixing and removal. Implicit Gear integration method was applied to solving the transient energy balance equations by taking initial time step 0.01 seconds, time step automatically adjusted depending on numerical convergence with maximum 1 second and minimum 0.001 seconds.

For the present analysis, two scenarios of the waste tank operations are considered to estimate thermal impact of Submersible Mixer Pumps (SMP's) on waste fluid during the process of waste removal. One scenario is the original operational plan. The original plan was the 10 days' initial mixing followed by three cycles of waste removal and refilling operations as shown in Fig. 4. The other scenario is related to the updated plan with 40 days' initial mixing with constant tank level, which was recently modified due to the proposed tank changes made as part of the initial draft review on the results of the original plan.

In this paper, the original plan is related to the shorter period of the initial mixing (10 days' initial mixing) with three cycles of waste removal and refilling operations (5 days' mixing for each cycle). The results for the continuous mixing with variable tank level are presented here since this scenario is the orginal choice for the operations of the SRS type- 1 tanks.

The primary goal of the present work is to assess the thermal performance impact of the slurry pumps on waste fluid in the process of sludge mixing and removal in the tank and to provide the operational information and design guidance for the replacement of the existing mixer pumps. In addition, sensitivity studies for the key variables of tank operation are performed to investigate what parameters are most sensitive to the thermal response of the waste tank to the SMP operations.

\subsection{Model Benchmarking}

The present model was benchmarked against the test data obtained by the Tank 11 measurement to examine the quantitative thermal response of tank waste to decay heat loads under no pump operation. HLW Engineering has made continuous measurements for the sludge and supernate 
temperatures for Tank 11 since January 1997. The measurement data for the one-month period of December 2000, when cooling coil system was restored from previously inactive status, was used for the model benchmarking. The reference operating conditions shown in Table 1 were used in the benchmarking. The thermal properties used in the calculations are shown in Table 2. The results showed that the model predictions agreed with the test data for the waste temperature within about $10 \%$ as shown in Fig. 5. Thus, the uncertainty of the present calculations was quantified by the benchmarking test for the reference operating conditions as defined in Table 1. In the calculations, 12 active cooling coils were used as one of the reference nominal operating conditions as established by the benchmarking test.

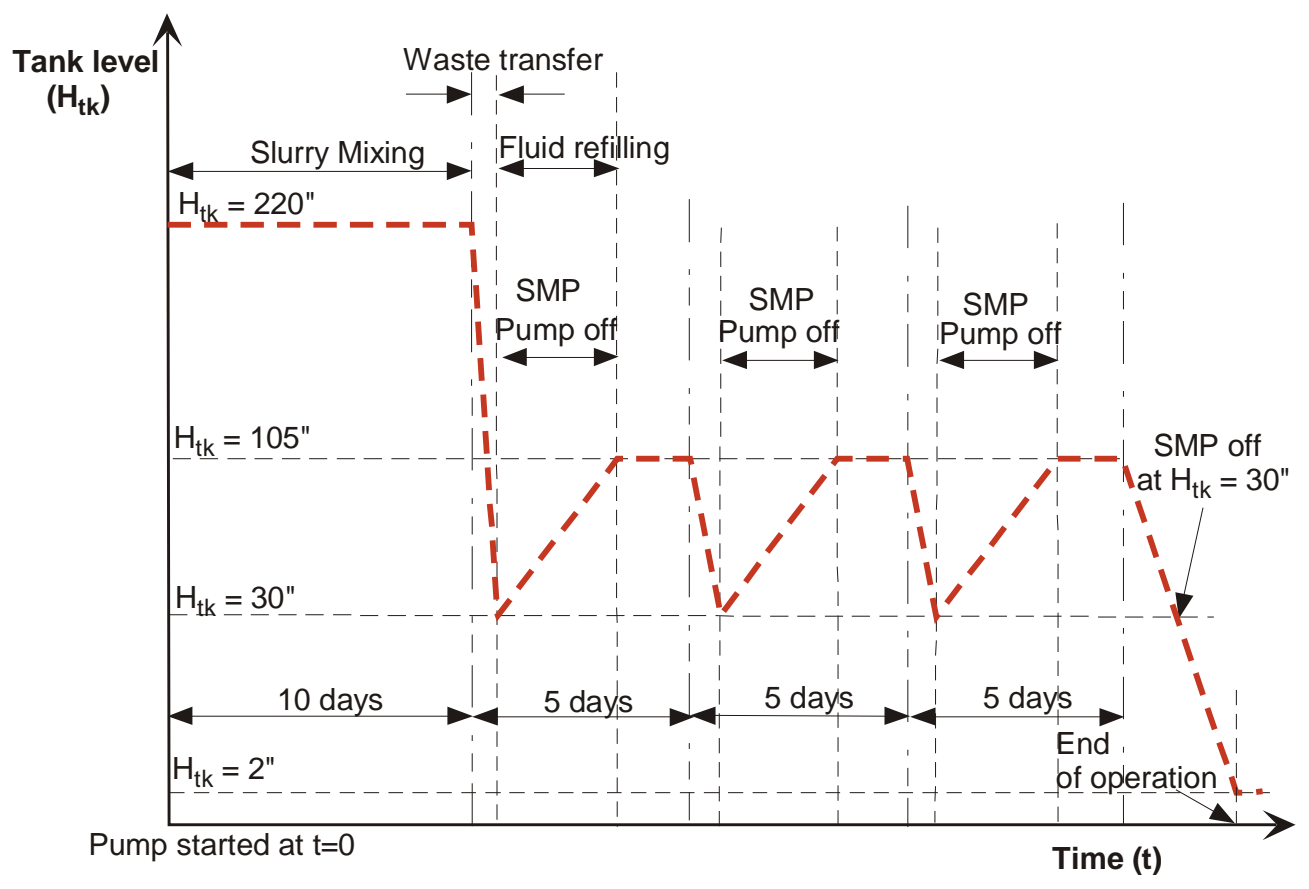

Figure 4. Slurry removal operating curve used in the present analysis 


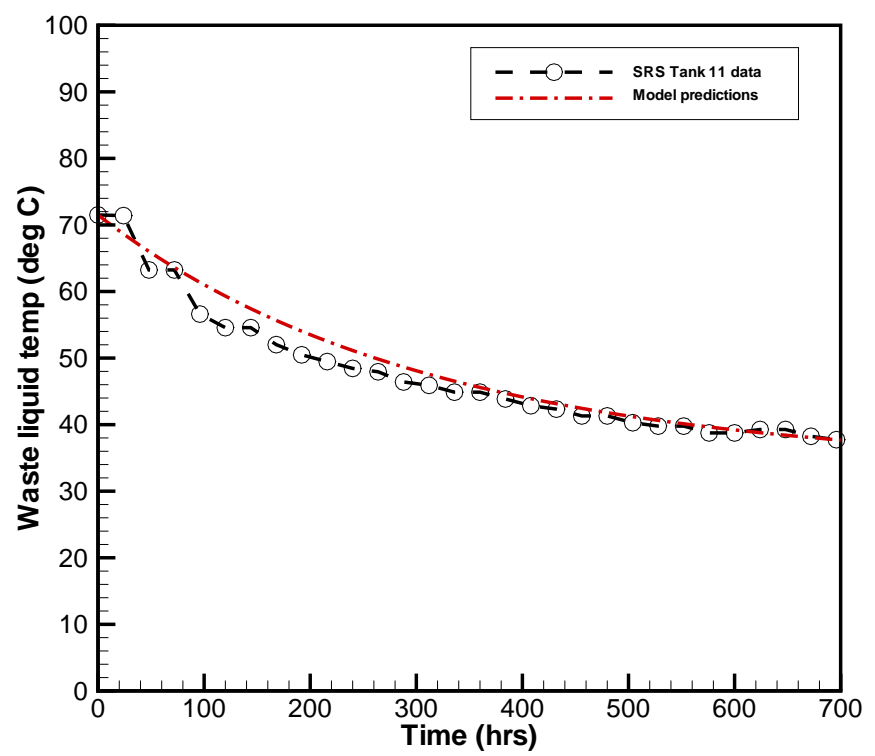

Figure 5. Comparison of transient waste temperatures between Tank 11 measurements and the model predictions for the reference conditions.

\subsection{Modeling Calculations and Sensitivity Results for Variable Tank Liquid Level}

The modeling calculations were performed under the variable tank level of the original operating plan as shown in Fig. 4. In addition, sensitivity studies for the key variables of tank operation were performed to investigate what parameters are most sensitive to the thermal response of the waste tank to the SMP operations. For the calculations, it was assumed that pumping energy of the slurry mixers and decay heat loads of the sludge waste were dissipated uniformly and instantaneously through the entire fluid region of the tank.

A series of the modeling calculations was performed to assess how submersible mixer pumps affect the tank fluid temperature during waste removal in type-I tank such as Tank 11 at SRS. As one of the reference conditions for the thermal analysis of the type-I tank, decay heat load of Tank 11 was used in the calculations since it has the highest decay heat source among the type-I tanks located in SRS F and $\mathrm{H}$ tank farm areas as shown in Table 1. When 100 inches of initial tank level and $65{ }^{\circ} \mathrm{C}$ of initial waste temperature were used as the reference conditions, maximum waste temperature was about $91{ }^{\circ} \mathrm{C}$ at the end of the first 260 hours' mixing operation, which is just before the beginning of the first tank refill. In the calculations, the tank operation curve shown in Fig. 4 was applied to the model as the transient boundary conditions. In this case, the dominant heat load comes from the operation of two 250 HP SMP mixers. The decay heat load corresponding to the waste content of Tank 11 is about only $10 \%$ of the heat dissipated by two SMP's. Those heat source and sink terms are quantitatively compared in Fig. 6. Transient temperatures of waste liquid, purge gas, and cooling coil exit for the reference operating conditions are shown in Fig. 7. As shown in the figure, it is noted that transient 
temperatures for the three key components approach constant maximum and minimum temperatures after the first 400 hours' operation, corresponding to 10 days' initial mixing and one 5 days' mixing cycle.

The results show that the cooling coil system is the dominant heat removal mechanism, compared to other potential heat sinks such as evaporative cooling from the top surface of the tank and conductive heat transfer through the tank wall. It is also shown that the purge gas temperature is more sensitive to the waste temperature at each transient time, compared to the cooling coil water since the gas specific heat is much smaller than the water.

Sensitivity runs have been performed to investigate what physical variables are most sensitive to the waste temperature with respect to the reference conditions. The sensitivity variables used for the analysis are listed in Table 3. Detailed sensitivity results for each variable are provided below.

\subsubsection{Decay Heat}

When average decay heat load $\left(21.8 \mathrm{~W} / \mathrm{m}^{3}\right)$ of the F-area tanks was used instead of the referenced decay heat $\left(42.6 \mathrm{~W} / \mathrm{m}^{3}\right)$ for the sensitivity run, maximum waste temperature was found to be about $89{ }^{\circ} \mathrm{C}$, which is $2{ }^{\circ} \mathrm{C}$ lower than the reference case, Tank 11 decay heat. In this case, other operating parameters including the initial waste temperature were kept at the reference values given in Table 1 . Waste temperature is not sensitive to the decay heat load since it is small fraction (about $10 \%$ ) of total heat load dissipated by the two SMP and one STP as discussed earlier. 
Table 1. Reference operating conditions for heat balance study of the type-1 waste tank

\begin{tabular}{|c|c|}
\hline Operating parameters & Reference operating conditions \\
\hline Tank dimension (diameter $\mathrm{x}$ height) & $75 \mathrm{ft} \times 24.5 \mathrm{ft}$ \\
\hline Initial temperature of waste fluid & $65{ }^{\circ} \mathrm{C}\left(40\right.$ and $\left.50{ }^{\circ} \mathrm{C}\right) *$ \\
\hline Initial tank level & 100 in (from 75 to 130 in)* \\
\hline Purge gas temperature at inlet & $25{ }^{\circ} \mathrm{C}$ \\
\hline Waste liquid density & $1.35 \mathrm{sg}(1.2,1.3$, and $1.4 \mathrm{sg}$ 's)* \\
\hline Coolant temperature at coil inlet & $25{ }^{\circ} \mathrm{C}$ \\
\hline Cooling coil surface condition & Surface with no chemical deposition \\
\hline $\begin{array}{l}\text { Number of operating cooling coils out of } \\
\text { total } 36 \text { cooling coils }\end{array}$ & $12(11)^{*}$ \\
\hline Bottom cooling coil availability & Not available \\
\hline Flowrate per cooling coil & $\begin{array}{l}5.7 \text { gpm corresponding to } 200 \text { gpm for } \\
35 \text { cooling coils }\end{array}$ \\
\hline Purge gas flowrate & 500 scfm (250scfm)* \\
\hline Relative humidity & $97 \%$ \\
\hline Number of operating pumps & 2 SMP's and 1 STP \\
\hline $\begin{array}{c}\text { Pumping power of each submersible mixing } \\
\text { pump (SMP) }\end{array}$ & $\begin{array}{c}250 \mathrm{HP} \text { (350 HP, } 300 \mathrm{HP} \text {, and } 225 \\
\text { HP)* }\end{array}$ \\
\hline $\begin{array}{c}\text { Pumping power of each submersible transfer } \\
\text { pump (STP) }\end{array}$ & $25 \mathrm{HP}$ \\
\hline Transfer pump flowrate & 200 gpm \\
\hline Tank refill flowrate & 31 gpm \\
\hline $\begin{array}{l}\text { Max. decay heat of Tank } 11 \text { waste (average } \\
\text { decay heat of type-I tanks) }\end{array}$ & $\begin{array}{c}42.58 \mathrm{~W} / \mathrm{m}^{3}[0.55 \mathrm{Btu} / \mathrm{hr} \text { gal }] \\
\left.\mathrm{W} / \mathrm{m}^{3}[0.28 \mathrm{Btu} / \mathrm{hr} \text { gal }]\right)^{*}\end{array}$ \\
\hline
\end{tabular}

Note: *conditions used for the sensitivity analysis of the present model 
Table 2. Thermal and heat transfer properties of tank components used for the present analysis

\begin{tabular}{|c|c|c|}
\hline Region (material) [Ref.] & $\begin{array}{c}\text { Material } \\
\text { thickness }\end{array}$ & $\begin{array}{c}\text { Thermal conductivity or heat transfer } \\
\text { coeff. used in the analysis }\end{array}$ \\
\hline $\begin{array}{c}\text { Cooling coil (carbon steel) } \\
\text { [Rohsenow and Choi, 1961] }\end{array}$ & 0.154 in & $43.24(\mathrm{~W} / \mathrm{mK})$ \\
\hline $\begin{array}{c}\text { Waste liquid (slurry) } \\
\text { [Kays and Crawford, 1980] }\end{array}$ & --- & $0.615(\mathrm{~W} / \mathrm{mK})$ \\
\hline $\begin{array}{c}\text { Waste liquid film (water) } \\
\text { [Kays and Crawford, 1980] }\end{array}$ & --- & $0.1173\left(\mathrm{~W} / \mathrm{m}^{2} \mathrm{~K}\right)^{*}$ \\
\hline $\begin{array}{c}\text { Purge gas film layer (air) } \\
\text { [Holman, 1969] }\end{array}$ & --- & $0.5\left(\mathrm{~W} / \mathrm{m}^{2} \mathrm{~K}\right)^{* *}$ \\
\hline $\begin{array}{c}\text { Tank wall (carbon steel) } \\
\text { [Rohsenow and Choi, 1961] }\end{array}$ & 0.5 in & $43.24(\mathrm{~W} / \mathrm{mK})$ \\
\hline $\begin{array}{c}\text { Chemical deposition layer } \\
\text { (salt compound) [SRS-HLW] }\end{array}$ & 0.5 in*** \\
\hline $\begin{array}{c}\text { Concrete } \\
\text { [Rohsenow and Choi, 1961] }\end{array}$ & 30 in & $0.43(\mathrm{~W} / \mathrm{mK})$ \\
\hline $\begin{array}{c}\text { Soil } \\
\text { [Marsily, 1986] }\end{array}$ & --- & $1.107(\mathrm{~W} / \mathrm{mK})$ \\
\hline
\end{tabular}

Note:* Heat transfer coefficient is based on constant wall heat flux correlation available in the literature.

** Heat transfer coefficient is based on natural convection correlation for flat plate available in the literature.

*** Data provided by the customer (for tank wall and bottom)

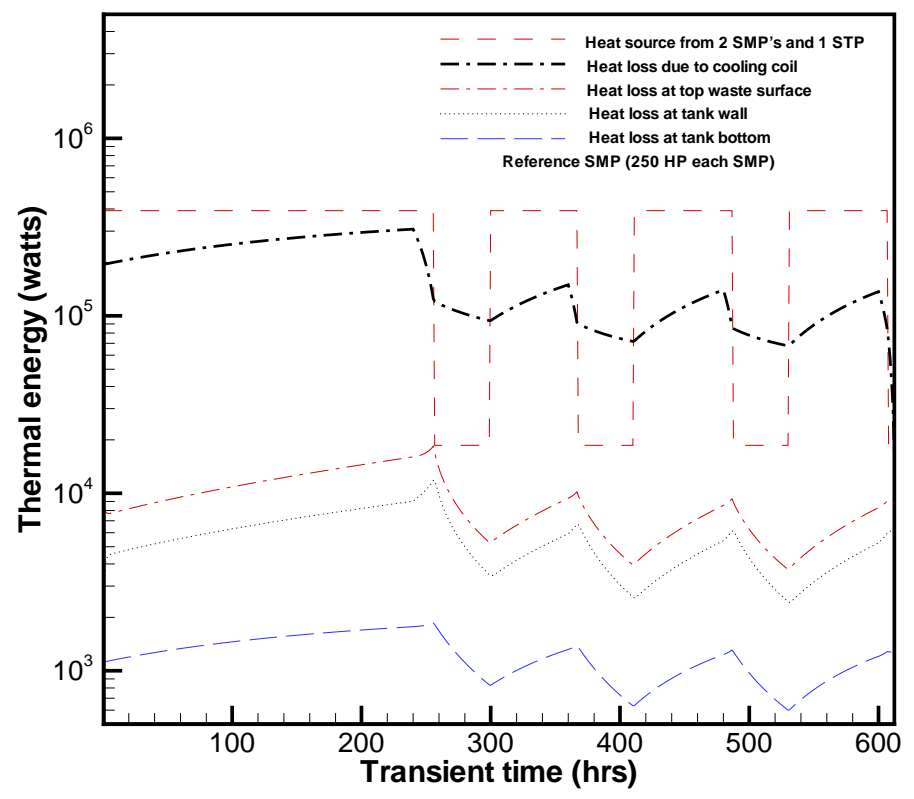

Figure 6. Transient heat source and sink for the reference operating conditions as shown in Table 1 


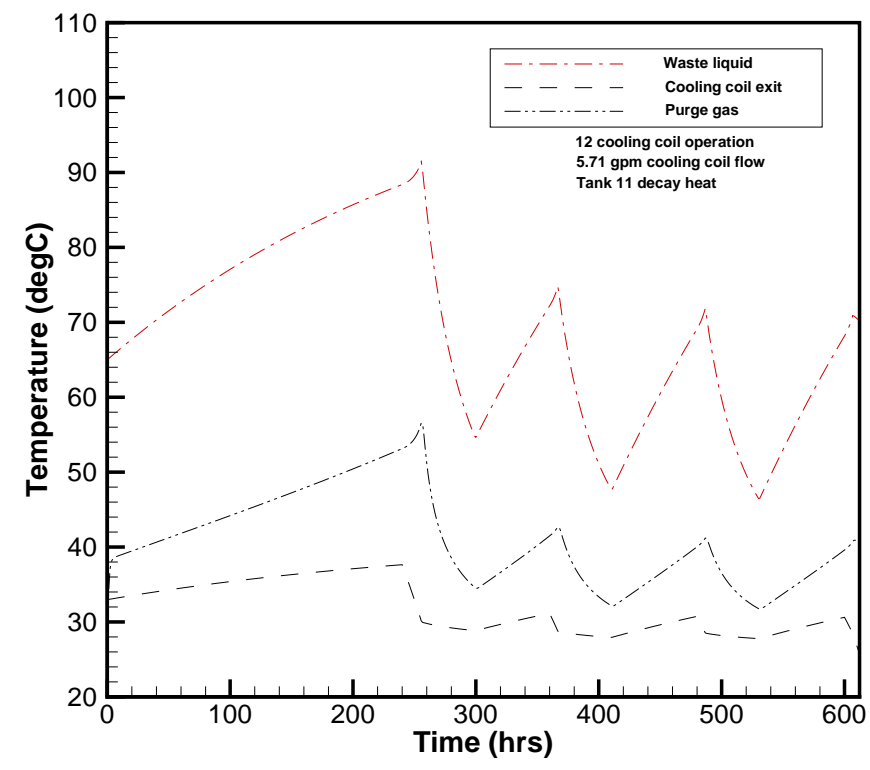

Figure 7. Transient temperatures of waste liquid, purge gas, cooling coil exit for the reference operating conditions as shown in Table 1

Table 3. Parameters used for the sensitivity study of the type-1 waste tank analysis

\begin{tabular}{|c|c|}
\hline $\begin{array}{l}\text { Operating or physical parameters } \\
\text { (dimension unit) }\end{array}$ & Sensitivity study ranges of each parameter \\
\hline Decay heat $\left(\mathrm{W} / \mathrm{m}^{3}\right)$ & From 21.76 (avg.) to 42.58 (Tank 11)* \\
\hline Initial temperature of waste liquid $\left({ }^{\circ} \mathrm{C}\right)$ & From 40 to $65^{*}$ \\
\hline Ambient temperature $\left({ }^{\circ} \mathrm{C}\right)$ & From 10 to $41.7,(25)^{*}$ \\
\hline Cooling coil flowrate (gpm) & From $0.0^{* *}$ to $7.45,(5.71)^{*}$ \\
\hline Number of cooling coils operated (---) & From 11 to $12^{*}$ \\
\hline $\begin{array}{l}\text { Bottom cooling coil availability among } \\
\text { the active cooling coils (---) }\end{array}$ & $\begin{array}{l}\text { From no bottom coil available* to one bottom coil } \\
\text { available }\end{array}$ \\
\hline Purge gas flowrate (scfm) & From 250 to $500 *$ \\
\hline Max. evaporation rate $\left(\mathrm{lbm} / \mathrm{ft}^{2} \mathrm{hr}\right)$ & From $0.795 *$ to 2.140 \\
\hline Initial tank liquid level (inches) & From 75 to $130,(100)^{*}$ \\
\hline Number of SMP operations (---) & From 1 to $2 *$ \\
\hline SMP powers (HP) & From 225 to $350,(250)^{*}$ \\
\hline Waste fluid density (s.g.) & From 1.2 to $1.4,(1.35)^{*}$ \\
\hline
\end{tabular}

Note: * Nominal reference operating conditions in the present analysis.

** Zero flow is equivalent to failure of all the remaining 12 operational coils. 


\subsubsection{Initial Waste Temperature and Ambient Temperature}

When initial waste liquid temperature changes from the reference condition $\left(65{ }^{\circ} \mathrm{C}\right)$ to $40{ }^{\circ} \mathrm{C}$, maximum waste temperature for the $40^{\circ} \mathrm{C}$ case is about $10^{\circ} \mathrm{C}$ lower than the reference case near 260 hours' transient time from the beginning of operation, which is just before the first cycle of tank refill. The temperature difference becomes smaller and smaller with transient time after the first cycle operation.

Ambient temperature is assumed to be $25^{\circ} \mathrm{C}$ in the reference run as shown in Table 1 . The inlet temperature of the purge gas and its initial gas temperature are assumed to be equal to ambient temperatures. In this case, the inlet temperature of the cooling coil water is also assumed to be ambient temperature to estimate the thermal impact of tank waste, since the exit water of the cooling coil is indirectly cooled by ambient temperature through heat exchanger such as cooling tower.

For the sensitivity runs with respect to ambient temperature, three different ambient temperatures, $10^{\circ} \mathrm{C}, 25{ }^{\circ} \mathrm{C}$, and $42{ }^{\circ} \mathrm{C}$, were considered including the reference value. For the reference tank level (100 in), maximum waste temperature varied from $84^{\circ} \mathrm{C}$ to $99{ }^{\circ} \mathrm{C}$ when ambient temperature changes from $10{ }^{\circ} \mathrm{C}$ to $42{ }^{\circ} \mathrm{C}$. Transient waste temperatures are compared among the three cases of different ambient temperatures in Fig. 8. It is noted that when initial tank level becomes higher, maximum waste temperature is more sensitive to ambient temperature because of the increased wet surface area of the cooling coils.

When only the inlet and initial temperatures of the purge gas are used as the sensitivity parameter, and other operating parameters including the inlet temperature of the cooling coil are kept as the reference values, the results show that they are not sensitive to the waste temperature. For instance, maximum waste temperature is increased by about $0.4{ }^{\circ} \mathrm{C}$ when ambient temperature changes from $25{ }^{\circ} \mathrm{C}$ to $42{ }^{\circ} \mathrm{C}$.

\subsubsection{Cooling Coil Flowrate}

As discussed earlier, the calculation results for the reference conditions show that heat loss through the cooling coil system is the most dominant among the other heat sink mechanisms provided in the waste tank system. In this case, $5.71 \mathrm{gpm}$ of cooling coil flow and 12 active coils out of total 36 possible cooling coils were used as the reference operating conditions since they were established by the benchmarking test and the operating information.

Several different cases for zero to $7.45 \mathrm{gpm}$ flowrates were used for the sensitivity runs of the cooling coil flow. For instance, when the cooling coil flow increased from 5.71 gpm to 7.45 gpm, the maximum waste temperature decreased by about $1{ }^{\circ} \mathrm{C}$ due to the increased convective energy transport and maximum coolant exit temperature decreased by about $3{ }^{\circ} \mathrm{C}$. In this situation, the impact of cooling coil flow on the waste temperature was also assumed under different initial tank liquid levels. The results show that maximum waste temperature for the referenced cooling coil flow $(5.71 \mathrm{gpm})$ is consistently about $1^{\circ} \mathrm{C}$ higher than the case of 7.45 gpm flowrate for various tank levels.

For zero flowrate of the cooling coil system, it was assumed that pumping heat and decay heat loads were cooled by natural convection inside the cooling coil, which contains a stagnant water medium of about $1.257 \mathrm{~m}^{3}$ total volume. For the present conditions, heat transfer coefficient at the inner wall of the cooling coil was found to be about $242.13 \mathrm{~W} / \mathrm{m}^{2} \mathrm{~K}$. The results showed that maximum waste temperature would increase up to about $129{ }^{\circ} \mathrm{C}$ for the referenced tank level (100 in). 


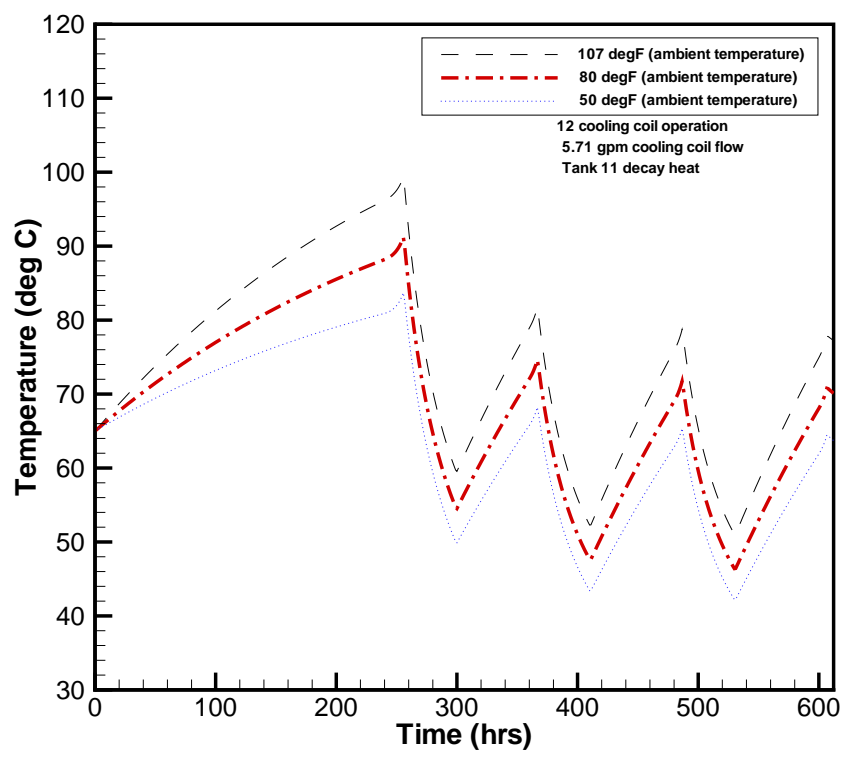

Figure 8. Comparison of maximum temperatures of waste fluid for different ambient temperatures using the reference operating conditions of the other parameters as shown in Table 1

\subsubsection{Number of Active Cooling Coils}

As mentioned earlier, 12 coils out of total 36 cooling coils were assumed to be active as one of the reference operating conditions from the benchmarking test. In this case, the cooling coil located near the bottom of the tank was assumed to be inactive for conservative estimation of waste temperature since the entire cooling coil is spread horizontally above the bottom surface of the tank and it has $100 \%$ wetted coil surface. Another reason for this was to consider the fact that the bottom coil has poor heat transfer capability due to fouling of the coil surface as provided by the operating information.

When one bottom coil out of 12 total active cooling coils was assumed to be active, maximum waste temperature decreased by about $8{ }^{\circ} \mathrm{C}$, compared to the reference case. As the initial tank level increased, the difference of maximum waste temperatures between the two cases decreased since the cooling capability of the other 11 vertical cooling coils increased due to the increase of wetted surface area.

When the number of active cooling coils is reduced from the reference number (12 coils) to 11 coils for the 100-in reference tank level, maximum waste temperature increased by $2{ }^{\circ} \mathrm{C}$ with respect to the reference results. Considering the large liquid volume in the tank, i.e., about 1,000 $\mathrm{m}^{3}$ for the reference liquid level, a temperature rise of $2{ }^{\circ} \mathrm{C}$ requires a significant transfer of heat and indicates that the thermal balance is very sensitive to the cooling coil surface.

\subsubsection{Purge Gas Flowrate}

As shown in Table 2, 500 scfm purge gas flow was used as one of the reference operating conditions. Sensitivity study of the gas flow was performed to examine how gas flow affects the 
coolability of the waste tank system. When the gas flow changed from the reference value (500 scfm) to $250 \mathrm{scfm}$, maximum temperatures of waste and coolant coil water were changed less than $1{ }^{\circ} \mathrm{C}$, but the gas temperature was increased by about $9{ }^{\circ} \mathrm{C}$ since specific heat capacity of gas is much smaller than that of the liquid waste.

\subsubsection{Evaporation Rate}

As discussed earlier, the reference conditions were established by the benchmarking test. As one of the reference operating conditions, about $0.8 \mathrm{lbm} / \mathrm{ft}^{2} \mathrm{hr}$ of evaporation rate was used for the modeling calculations. For the sensitivity analysis, three different values of the evaporation rate were applied to the present model. The calculation results showed that maximum temperature of the waste tank was not sensitive to different evaporation rates since more evaporation rate caused the gas temperature to be raised and then made sensible heat loss smaller for the reduced temperature difference between the gas and the waste fluid at the free surface of the tank.

\subsubsection{Initial Tank Level}

The 100-in initial tank level was used as one of the reference operating conditions as provided by the operational procedure of waste removal. Sensitivity studies of the initial tank level were performed to examine the temperature responses of the waste tank system to different tank levels. When the initial tank level changed from the reference level, 100 in, to the reduced level, 75 in, maximum waste temperature increased by $9{ }^{\circ} \mathrm{C}$.

\subsubsection{Powers of Submersible Mixer Pump (SMP)}

Transient calculations have been made for the 25-day operation of the mixing and three-cycle sludge removal to estimate transient waste temperatures within type-I waste tank when the tank has two Submersible Mixer Pumps (SMP's) and one Submersible Transfer Pump (STP) for sludge removal operation as the reference conditions.

As discussed earlier, the dominant heat load is from the operation of two 250 HP SMP mixers, and the highest decay heat load among the type-I waste tanks, which is generated by the Tank 11 waste, is about only $10 \%$ of the two-SMP dissipation heat. In this case, when the number of the SMP units is reduced from two to one, maximum waste temperature decreased by $18{ }^{\circ} \mathrm{C}$ under the reference tank level.

In case of two mixer operation, the impact of the SMP powers on maximum tank temperature was also examined. When each power of the two SMP mixers increased from 225 to 350 horsepower, maximum temperature of the waste tank changed from $87{ }^{\circ} \mathrm{C}$ to $106{ }^{\circ} \mathrm{C}$ under the reference tank level. For instance, the maximum temperature reached $106{ }^{\circ} \mathrm{C}$ when each SMP power has 350 horsepower.

When the tank was assumed to have average decay heat load (21.76 W/m $\mathrm{m}^{3}$ in Table 1$)$ and each SMP increased from 300 to 350 horsepower, maximum temperature was found to be about 104 ${ }^{\circ} \mathrm{C}$, which is $2{ }^{\circ} \mathrm{C}$ lower than the reference case of Tank 11 decay heat. Transient temperatures of the waste fluid with average decay heat are compared for the three different powers of SMP in Fig. 9. 


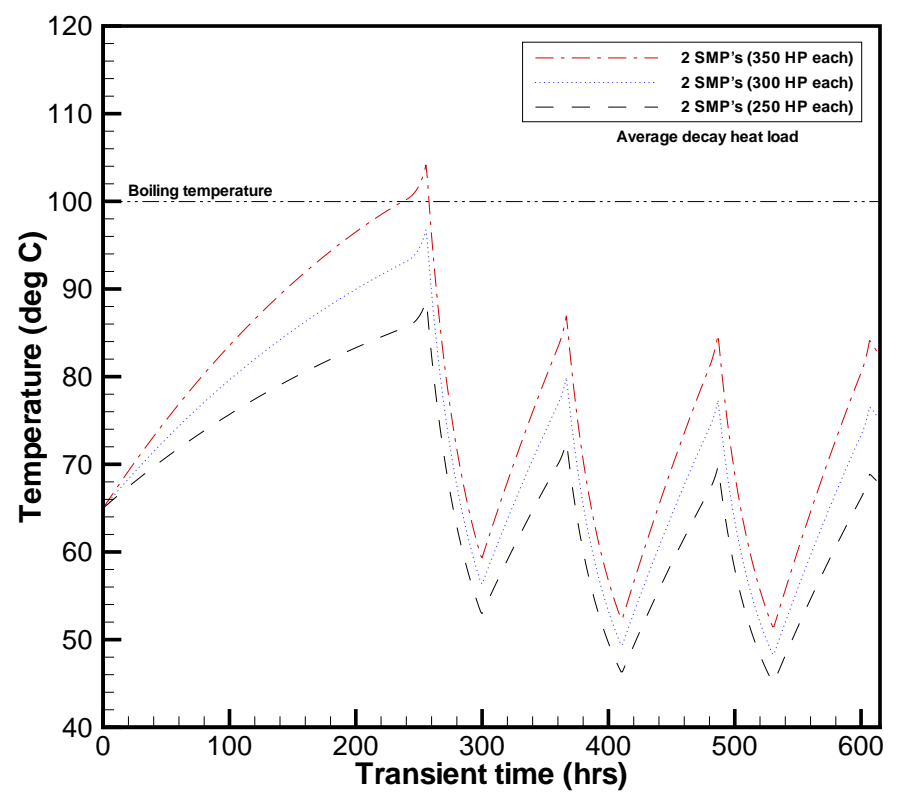

Figure 9. Transient temperatures of waste fluid with average decay heat of type-I tanks for three different SMP powers under the reference conditions of the other parameters as shown in Table 1

\subsubsection{Waste Fluid Density}

As shown in Table 1, 1.35 specific gravity (sg) of waste density was used as one of the reference operating conditions. For the sensitivity analysis of the waste fluid properties, different densities of 1.2 to $1.4 \mathrm{sg}$ were used for the same specific heat. When the waste density was reduced from the reference value $(1.35 \mathrm{sg})$ to $1.2 \mathrm{sg}$, maximum waste temperature was increased by $3{ }^{\circ} \mathrm{C}$.

For the reference operating conditions except for waste density, the transient calculations for four different waste densities have been performed to examine the sensitivity of waste temperature associated with the change of waste material property. The results showed that maximum waste temperature for the density change of 1.4 to $1.2 \mathrm{sg}$ was changed by about $3{ }^{\circ} \mathrm{C}$.

Sensitivity study for the operating parameters was performed by the heat balance model for the tank type-I waste storage system with SMP operation. The results show that number of active cooling coils and coil flowrate are dominant cooling mechanisms to control waste tank temperature for given SMP mixer power. As discussed earlier, the nominal reference conditions defined in Table 1 are considered the best-estimate operating values. The results show that the waste temperature rises a maximum $6{ }^{\circ} \mathrm{C}$ in 48 hours under the reference operating conditions. Figure 10 shows transient peak temperatures of waste during 25 days' operations with two 250hp SMP. As shown in the figure, the waste fluid reaches steady temperature cycling in about 400 hours since the initiation of tank operations under the reference conditions. It is also emphasized that the power dissipated by the SMP mixers provides the dominant heat source term, compared 
to the radioactive decay heat load of the tank waste. Table 3 shows a summary of the sensitivity parameters performed in the present analysis.

From the heat balance analysis, it is concluded that maximum temperature of the tank type-I waste will remain below boiling temperature $\left(100{ }^{\circ} \mathrm{C}\right)$ when waste removal is processed with the heat source terms of two units of 250 HP SMP mixers and Tank 11 decay heat. The analysis used the reference operating conditions listed in Table 1 and the operational procedure of waste removal shown in Fig. 4. All the sensitivity analyses demonstrate that maintaining active cooling coil system provides important cooling mechanism to remove the process heat from the waste tank system.

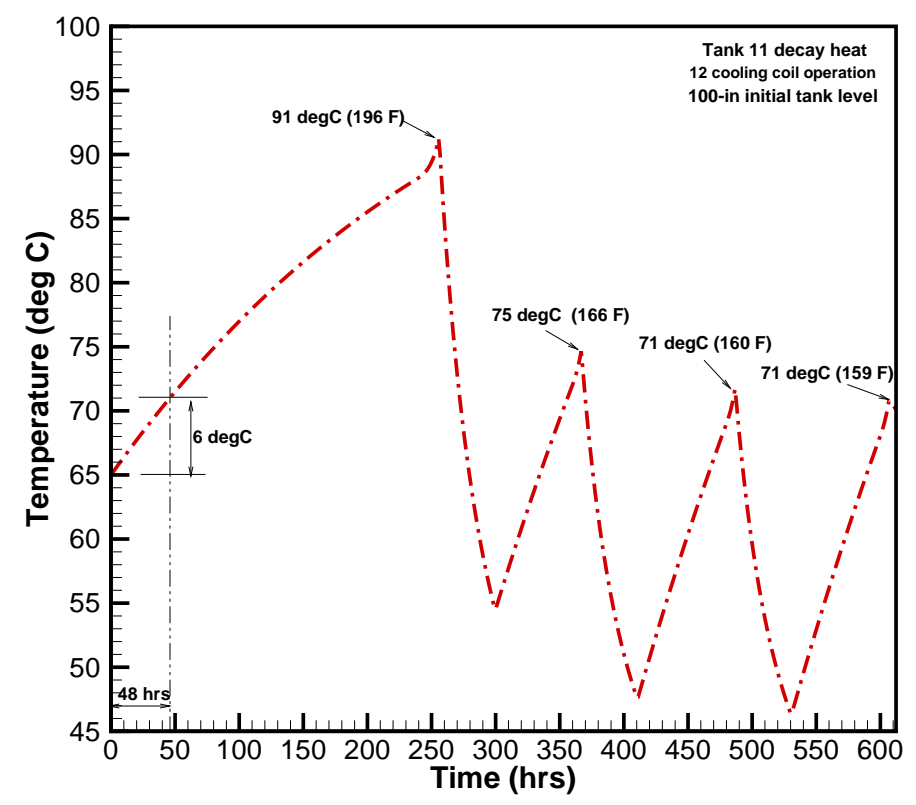

Figure 10. Transient waste temperatures for the reference nominal operating conditions showing maximum $6^{\circ} \mathrm{C}$ temperature increase in 48 hours

\section{CONCLUSIONS}

A lumped parametric approach was taken to develop a transient model for the heat balance study for type-I tank waste during the waste removal operated by the SMP mixers. The tank domain used in the model includes two SMP's for the sludge mixing, one Submersible Transfer Pump (STP) for the waste removal, a cooling coil system with 12 active coils as one of the reference nominal conditions, and purge gas system. All the governing equations were established by the overall energy balance for the modeling domain, and they were numerically solved. The results computed by the present model with no SMP operation were compared with test data for benchmarking. The results showed that the model predictions agreed with the test data for the waste temperature within about $10 \%$. 
In the analysis potential operational scenario was considered for transient modeling calculations to estimate transient waste temperature for the operational domain and to perform the sensitivity studies of key operating parameters. It is 10 days' initial mixing followed by 15 days of subsequent three-cycle waste removal operation as an original option. The modeling results for the original option including the detailed sensitivity analyses for all physical parameters related to the tank operations are presented here.

The sensitivity results show that the number of active cooling coils and coil flowrate are dominant cooling mechanisms to control waste tank temperature for given SMP power and decay heat load. It is emphasized that the power dissipated by SMP provides dominant heat source term, compared to the radioactive decay heat load of the type-I tank waste. It is concluded that maximum temperature of tank waste will remain below boiling temperature when radioactive liquid waste mixing is processed under the reference operating conditions including the heat source terms of two units of 250-HP SMP mixers and Tank 11 decay heat.

\section{ACKNOWLEDGMENT}

This work was funded by U.S. Department of Energy and performed at the Savannah River National Laboratory, which is operated by Savannah River Nuclear Solutions, LLC.

\section{REFERENCES}

1. E. J. Freed and P. S. Mukherjee, 2001, “Tank 8 Waste Rremoval Operating Plan”, U-ESRF-00009, Rev. 5, April.

2. S. Y. Lee, R. A. Dimenna, R. A. Leishear, D. B. Stefanko, 2008, “Analysis of Turbulent Mixing Jets in a Large Scale Tank”, ASME Journal of Fluids Engineering, 130 (1), pp. 011104.

3. S. E. Aleman, G. P. Flach, L. L. Hamm, S. Y. Lee, and F. G. Smith, III, 1993, "FLOWTRAN-TF Software Design (U)", WSRC-TR-92-532, February.

4. W. M. Kays and M. E. Crawford, 1980, Convective Heat and Mass Transfer, $2^{\text {nd }}$ edition, McGraw-Hill Book Co, New York.

5. J. P. Holman, 1980, Heat Transfer, $4^{\text {th }}$ edition, McGraw-Hill Book Co, New York.

6. H. Schlichting, 1967, Boundary Layer Theory, McGraw-Hill Book Company, New York.

7. W. M. Rohsenow and H. Y. Choi, 1961, Heat, Mass, and Momentum Transfer, PrenticeHall, Inc., New Jersey.

8. F. P. Incropera and D. P. DeWitt, 1981, Fundamentals of Heat and Mass Transfer, $2^{\text {nd }}$ edition, John Wiley \& Sons.

9. S. W. Churchill and H. H. S. Chu, 1975, "Correlating Equations for Laminar and Turbulent Free Convection from a Vertical Plane”, Int. Journal of Heat Mass Transfer, 18, pp. 1323.

10. Ghislain de Marsily, 1986, Quantitative Hydrogeology, Groundwater Hydrology for Engineers, Translated by Gunilla de Marsily, Academic Press, Inc., New York.

11. J. H. Perry, Chemical Engineers' Handbook, Fourth Edition, McGraw-Hill Book Co, New York. 